Supplementary Information (SI)

\title{
Atmospheric Atrazine at Canadian IADN Sites
}

Yuan Yao, Elisabeth Galarneau, Pierrette Blanchard *, Nick Alexandrou, Kenneth A. Brice, and Yi-Fan Li

Science and Technology Branch, Environment Canada, 4905 Dufferin Street, Toronto, ON, M3H 5T4, Canada

* Corresponding author phone: + 1416739 5701; fax: + 1416739 4281; e-mail address: pierrette.blanchard@ec.gc.ca.

\section{Content}

Page

\begin{tabular}{|l|l|l|}
\hline SI 1 & Extraction and cleanup of IADN samples & S2 \\
\hline Table S1 & GC/MS conditions used for IADN measurements & S3 \\
\hline Figure S1 & $\begin{array}{l}\text { Partition coefficient (log } \mathrm{K}_{\mathrm{p}} \text { ) as a function of inverse temperature at } \\
\text { Egbert, Point Petre and a single point at Burnt Island }\end{array}$ & $\mathrm{S} 4$ \\
\hline
\end{tabular}




\section{SI 1}

Extraction and Cleanup of IADN Samples. PUF and GFF samples were extracted separately. For PUF plugs, Soxhlet extraction was performed using hexane (475 mL) for $24 \mathrm{~h}$. The extracts were concentrated to $2 \mathrm{~mL}$ in isooctane, with half of this extract being used for atrazine determination. GFF samples were extracted by two approaches, namely Soxhlet extraction (for samples collected through 1998) and accelerated solvent extraction (ASE: introduced in early 1999 as a replacement for conventional Soxhlet method) (40). Dichloromethane (300 mL) was used for Soxhlet extraction (24 h). For ASE, the extractions were carried out using $30 \mathrm{~mL}$ hexane/acetone (70/30 v/v) for $25 \mathrm{~min}\left(100{ }^{\circ} \mathrm{C}, 2000 \mathrm{psi}\right)$. The mean recoveries for Soxhlet with DCM and ASE with hexane/acetone were 139\% and 114\%, respectively. GFF extracts were reduced in volume to $1 \mathrm{~mL}$ in either acetonitrile (for samples collected through April 2000) or isooctane (for subsequent samples). For a number of the sampling years (1996-1999), data for vapor-phase (i.e., PUF) atrazine have been derived by using Florisil column chromatography. The details of this procedure have been described elsewhere $(15,41)$. All the GFF extracts and the PUF extracts from samples collected from 2000 onwards were cleaned up using automated solid phase extraction (SPE). For GFF extracts from PPT up to the end of 2000, BNT up to April 2000, EGB up to August 2000, and PUF extracts for all three sites throughout 2000, a Waters Millilab 1A Workstation (Waters Canada) with silica cartridges (Waters SepPak Plus, $690 \mathrm{mg}$ ) was deployed, whereas a Hamilton Microlab 4000 system with 3-mL silica columns (Whatman, $690 \mathrm{mg}$ ) was used for subsequent samples. The collected atrazine fractions were concentrated and solvent exchanged into $1 \mathrm{~mL}$ in acetonitrile.

(40) Alexandrou, N.; Smith, M.; Park, R.; Lumb K.; Brice, K. A. The extraction of polycyclic aromatic hydrocarbons from atmospheric particulate matter samples by accelerated solvent extraction (ASE). Int. J. Environ. Anal. Chem. 2001, 81, 257-280.

(41) Cortes, D. R.; Basu, I.; Sweet, C. W.; Brice, K. A.; Hoff, R. M.; Hites, R. A. Temporal trends in gas-phase concentrations of chlorinated pesticides measured at the shores of the Great Lakes. Environ. Sci. Technol. 1998, 32, 1920-1927. 
Table S1. GC/MS Conditions Used for IADN Measurements

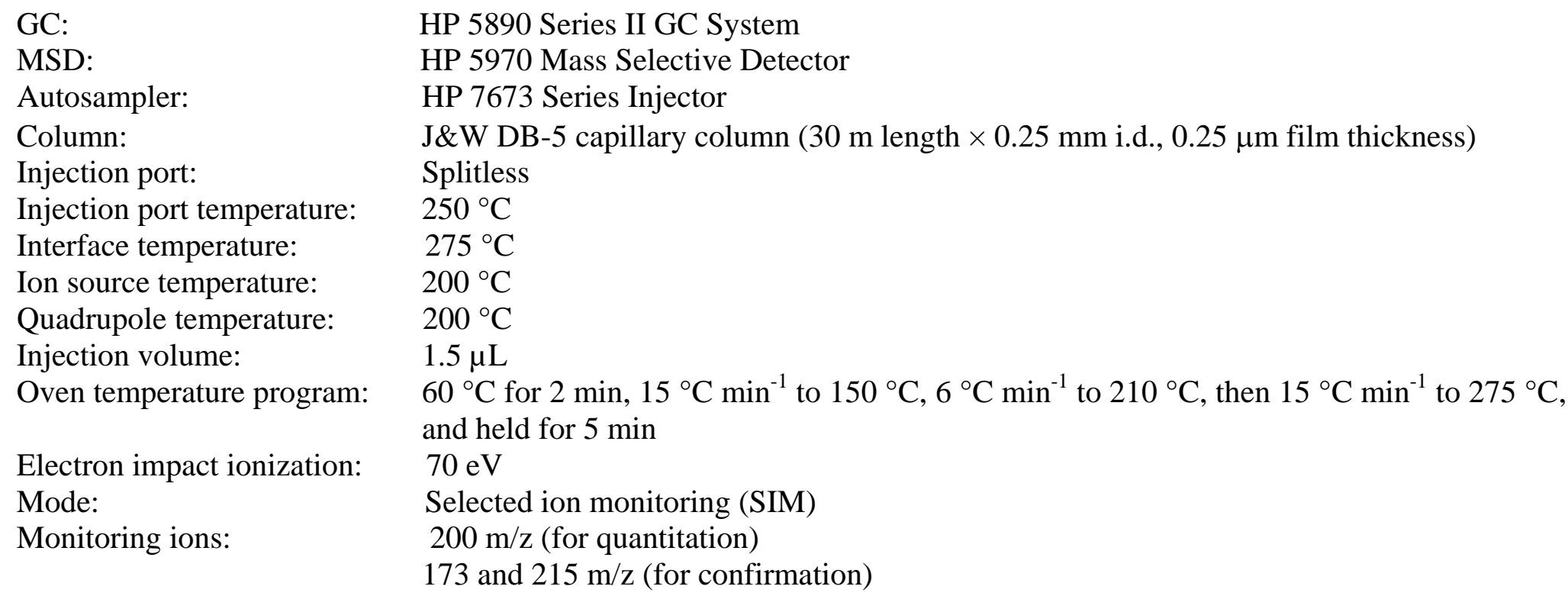

Electron impact ionization:

Mode:

Monitoring ions:

\section{HP 5890 Series II GC System \\ HP 5970 Mass Selective Detector}

HP 7673 Series Injector

J\&W DB-5 capillary column (30 m length $\times 0.25$ mm i.d., $0.25 \mu \mathrm{m}$ film thickness)

Splitless

$250{ }^{\circ} \mathrm{C}$

$275^{\circ} \mathrm{C}$

$200{ }^{\circ} \mathrm{C}$

$200{ }^{\circ} \mathrm{C}$

$1.5 \mu \mathrm{L}$

$60{ }^{\circ} \mathrm{C}$ for $2 \mathrm{~min}, 15^{\circ} \mathrm{C} \min ^{-1}$ to $150{ }^{\circ} \mathrm{C}, 6^{\circ} \mathrm{C} \min ^{-1}$ to $210^{\circ} \mathrm{C}$, then $15^{\circ} \mathrm{C} \min ^{-1}$ to $275^{\circ} \mathrm{C}$, and held for 5 min

$70 \mathrm{eV}$

Selected ion monitoring (SIM)

$200 \mathrm{~m} / \mathrm{z}$ (for quantitation)

173 and $215 \mathrm{~m} / \mathrm{z}$ (for confirmation) 


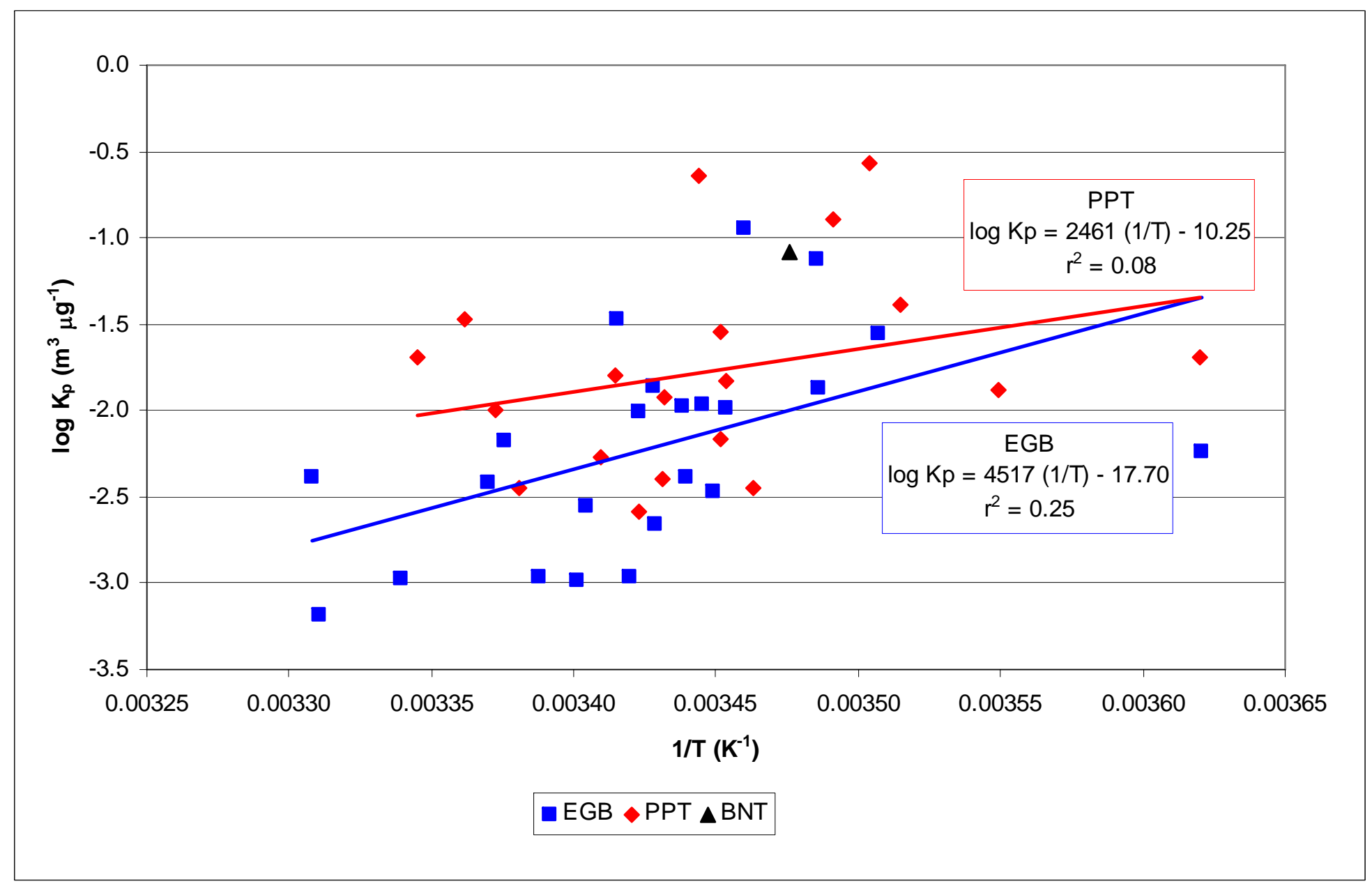

Figure S1. Partition coefficient $\left(\log \mathrm{K}_{\mathrm{p}}\right.$ ) as a function of inverse temperature at Egbert, Point Petre and a single point at Burnt Island. 